\title{
25-hydroxy Vitamin D Levels in Pediatric Asthma Patients and its Link with Asthma Severity
}

\author{
Gulten Ozturk Thomas ${ }^{1}$, Engin Tutar ${ }^{1}$, Gulnur Tokuc ${ }^{1}$, Sedat Oktem ${ }^{1}$ \\ 1. Pediatrics, Dr. Lutfi Kirdar Training \& Research Hospital, Istanbul, TUR
}

Corresponding author: Gulten Ozturk Thomas, gulten@thomas.md

\section{Abstract}

\section{Aim}

Although the relationship between 25-hydroxy (25-OH) vitamin D and asthma is known, it is unknown if $25-\mathrm{OH}$ vitamin D levels are correlated with asthma severity in pediatric patients. The aim of this study was to compare the blood 25-OH vitamin D levels of asthma patients and healthy control groups and to evaluate any correlation between asthma severity and blood $25-\mathrm{OH}$ vitamin $\mathrm{D}$ levels in pediatric asthma patients.

\section{Methods}

This is a cross-sectional study which shows the $25-\mathrm{OH}$ vitamin $\mathrm{D}$ levels of asthma patients and compared to healthy controls followed by a tertiary pediatric clinic. We investigated the effect of $25-\mathrm{OH}$ vitamin $\mathrm{D}$ levels on the severity of asthma. The severity of asthma was determined mainly by the duration of asthma diagnosis, a number of attacks in the previous year, anti-inflammatory medication usage in a previous year, atopy presence in the family, skin prick test positivity, and immunoglobulin E (IgE) levels of asthma patients.

\section{Results}

Compared with control groups, asthma patients had significantly lower $25-\mathrm{OH}$ vitamin D, calcium (Ca) levels, and higher number of patients who had a $25-\mathrm{OH}$ vitamin D deficiency, $(\mathrm{p}<0.0001, \mathrm{p}<0.0001$, $\mathrm{p}<0.0001$, respectively). We found a correlation between blood $25-\mathrm{OH}$ vitamin D levels and force expiratory capacity in one second (FEV1) and forced vital capacity (FVC) respectively $(p<0.001, r=0.512)$, $(p<0.001$, $\mathrm{r}=0.513)$. There was an association between FEV1, FVC and blood 25-OH vitamin D levels in terms of deficient levels $(<20 \mathrm{ng} / \mathrm{mL})$ or insufficient levels $(\geqslant 20$ and $<30 \mathrm{ng} / \mathrm{mL})(\mathrm{p}<0.001, \mathrm{r}=0.459),(\mathrm{p}<0.001, \mathrm{r}=0.450)$, respectively.

\section{Conclusions}

The 25-OH vitamin D levels were lower in pediatric asthma patients with worse spirometry results. Effects of Vitamin D supplementation need to be evaluated by well-designed studies.

Received 02/14/2019

Review began 03/10/2019

Review ended 03/12/2019

Published 03/22/2019

๑) Copyright 2019

Ozturk Thomas et al. This is an open access article distributed under the terms of the Creative Commons Attribution License CC-BY 3.0., which permits unrestricted use, distribution, and reproduction in any medium, provided the original author and source are credited.
Categories: Pediatrics

Keywords: asthma, 25-hydroxy vitamin d, disease severity

\section{Introduction}

Asthma - a chronic inflammatory disease characterized by recurrent episodes of wheezing, shortness of breath and coughing due to hyper-responsiveness of the airways, is one of the most common chronic diseases seen in childhood [1-2]. The prevalence of both asthma and 25-hydroxy (25-OH) vitamin D deficiency is reported to have increased in children [3-4] and one hypothesis for the rising prevalence of asthma involves 25-OH vitamin D deficiency [5-6]. Information from the International Study of Asthma and Allergy in Children (ISAAC) study group shows the highest prevalence of asthma in well-developed western countries [7]. Some authors have argued that 25-OH vitamin D has more of a deleterious effect on allergic pathogenesis [8]. Epidemiologic studies suggest that 25-OH vitamin D deficiency is also associated with an increased incidence of asthma symptoms [5]. There is limited data on 25-OH vitamin D levels in children with asthma, as well as on what features of pediatric asthma are associated with the 25-OH vitamin D levels. The prevalence of 25-OH vitamin D insufficiency/deficiency is higher for children living in Turkey [9]. A recent study on children with asthma from Costa Rica showed a significant inverse association between the 25-OH vitamin D levels and use of anti-inflammatory medication (either inhaled corticosteroid or leukotriene inhibitor) in the previous year, total immunoglobulin E (IgE), and eosinophil count [10]. These important findings require confirmation. The present knowledge about the relationship between $25-\mathrm{OH}$ vitamin D and asthma is still not enough to consider 25-OH vitamin D as an alternative or adjuvant treatment option in childhood asthma.

The aim of our study is to investigate blood 25-OH vitamin D levels of asthma patients followed by our 
outpatient clinic, compare it with healthy control groups and to evaluate any correlation between asthma severity and the blood 25-OH vitamin D levels.

\section{Materials And Methods \\ Subjects}

Children aged between 6 and 15 years with a diagnosis of asthma followed by the Pediatric Pulmonology Clinic of Dr. Lutfi Kurdar Kartal Research and Training Hospital were included in the study. A control group of healthy patients in the same age range was selected from among patients applying for a routine check-up to general pediatrics outpatient clinic. Patients were excluded if history revealed or it was documented in patients' files that they were taking $25-\mathrm{OH}$ vitamin D supplements, if they had additional chronic pulmonary conditions or if any infectious or chronic diseases were present. Data were collected between September December 2010 and September - December 2011. The study was designed as such to exclude any bias originating from the effect of seasonal sunshine on the blood $25-\mathrm{OH}$ vitamin D levels. Patients and controls were enrolled and their data were collected at the same season/time frame.

A questionnaire collecting sociodemographic information with questions to determine asthma severity in the patients was prepared by the authors and completed by patients' parents. 25-OH vitamin D supplementation history in the first year of life was queried.

The protocol was approved by the local Ethics Committee and informed consents were obtained from each parent, including consent for publication of data.

\section{Biochemical analysis}

Serum 25-OH vitamin D levels were analyzed photometrically by ROCHE DPP Modular system (Roche, Germany). Calcium (Ca), phosphorus (P) and alkaline phosphatase (ALP) levels were checked to exclude the patients with laboratory findings of rachitism. We categorized $25-\mathrm{OH}$ vitamin $\mathrm{D}$ levels as deficient $(<20$ $\mathrm{ng} / \mathrm{mL}$ ), insufficient $(\geqslant 20$ and $<30 \mathrm{ng} / \mathrm{mL}$ ), and sufficient $(\geqslant 30 \mathrm{ng} / \mathrm{mL}$ ) [11]. For quality control, samples were run in duplicate and the average measurement was taken.

\section{Pulmonary function tests}

Vital capacity and flow rates were measured by spirometry in accordance with the criteria of the American Thoracic Society (ATS) while patients were awake and in the seated position [12]. Spirometry was performed by one of the authors. The values of spirometry were expressed as the ratio of percentage of normal values based on age, gender, and height. The best value of a minimum of the three adequate measurements was taken. Reference values obtained in the study by Knudson, et al. [13] were used.

\section{Statistical analysis}

Statistical analysis was performed by Statistical Package for the Social Sciences (SPSS) 16.0. Continuous variables were described through means and standard deviations, whereas categorical variables were presented as proportions. Categorical variables were compared with Chi-square and with Fisher's exact test when $20 \%$ of the expected frequencies were less than five. Continuous variables among two groups were compared with Student T-test, since the data followed a normal distribution. Bivariate correlations were evaluated through Pearson correlation. Spearman correlation was used to analyze the relation between FEV1, FVC and blood 25-OH vitamin D levels in terms of deficient or insufficient. A p-value $<0.05$ was considered as statistically significant.

\section{Results}

\section{Subject characteristics}

Seventy-three patients with asthma (40 male, 33 female) and an average age of $10.2 \pm 2.7$ years (range 6-15 years) were enrolled in the study. The control group consisted of 44 healthy subjects ( 24 males, 20 females) without any chronic disease or infection, in the same age range (average age: $10.0 \pm 2.6$ years). There was no statistically significant difference between the two groups in terms of age, gender, P and ALP levels. There was no statistical difference between the $25-\mathrm{OH}$ vitamin D levels according to gender and age $(\mathrm{p}>0.05)$.

Demographic information, biochemical analyses and 25-OH vitamin D data for all subjects are shown in Table 1. 


\section{Cureus}

\begin{tabular}{|c|c|c|c|}
\hline & Asthma Group & Control Group & p \\
\hline Age (Years) & $10.2 \pm 2.7$ & $9.95 \pm 2.56$ & $\mathrm{p}=0.636$ \\
\hline Gender, Male/Female (n) & $40 / 33$ & $24 / 20$ & $\mathrm{P}=0.979$ \\
\hline Average $25-\mathrm{OH}$ vitamin D level, $\mathrm{ng} / \mathrm{ml}$ & $12.1 \pm 7.43$ & $19.8 \pm 1.02$ & $p<0.001$ \\
\hline Patients with $25-\mathrm{OH}$ vitamin D deficiency $(<20 \mathrm{ng} / \mathrm{ml})-\mathrm{n}(\%)$ & $60(82.2)$ & $21(47.7)$ & \\
\hline Patients with $25-\mathrm{OH}$ vitamin $\mathrm{D}$ insufficient $(\geq 20$ and $<30 \mathrm{ng} / \mathrm{mL}$ ) - $\mathrm{n}(\%)$ & $13(17.8)$ & 15(34) & $p<0.001$ \\
\hline Patients with $25-\mathrm{OH}$ vitamin D sufficient $(\geq 30 \mathrm{ng} / \mathrm{mL}$ ) - $\mathrm{n}(\%)$ & 0 & $8(18.2)$ & \\
\hline $\mathrm{Ca}, \mathrm{mg} / \mathrm{dl}$ & $9.47 \pm 0.4$ & $9.82 \pm 0.52$ & $\mathrm{P}<0.001$ \\
\hline $\mathrm{P}, \mathrm{mg} / \mathrm{dl}$ & $4.62 \pm 0.54$ & $4.72 \pm 0.53$ & $\mathrm{p}=0.196$ \\
\hline ALP, $\mathrm{mg} / \mathrm{dl}$ & $210 \pm 82$ & $226.35 \pm 72$ & $\mathrm{p}=0.372$ \\
\hline
\end{tabular}

TABLE 1: Demographic, biochemical analyses and 25-hydroxy vitamin D level data for asthma patients and control subjects

\#: Student t test, +: Chi square test, Ca: Calcium, P: Phosphorus, ALP: Alkaline phosphatase, 25-OH: 25-hydroxy

Compared with control groups, asthma patients had significantly lower 25-OH vitamin D and Ca levels, and the asthma group had higher number of patients who had $25-\mathrm{OH}$ vitamin D deficiency $(\mathrm{p}<0.001, \mathrm{p}<0.001$, $\mathrm{p}<0.001$, respectively).

\section{Clinical associations}

There was no relationship between the blood 25-OH vitamin D levels and the time since asthma diagnosis, the number of attacks, inhaled steroid, systemic steroid or anti-inflammatory (either inhaled corticosteroșds or leukotriene inhibitors) medication use during the last year, atopy in the family, skin prick test positivity, $25-\mathrm{OH}$ vitamin D usage in first year of life and Ig E levels in asthma patients ( $\mathrm{p}>0.05)$.

The blood 25-OH vitamin D levels were found to correlate with forced expiratory volume in the first second (FEV1) and forced vital capacity (FVC) ( $\mathrm{p}<0.001, \mathrm{r}=0.512$ and $\mathrm{p}<0.001, \mathrm{r}=0.513$, respectively.) Also, there was an association between FEV1, FVC and blood 25-OH vitamin D levels for the groups with deficient levels $(<20 \mathrm{ng} / \mathrm{mL})$ or insufficient levels $(\geqslant 20$ and $<30 \mathrm{ng} / \mathrm{mL})(\mathrm{p}<0.001, \mathrm{r}=0.459$ and $\mathrm{p}<0.001, \mathrm{r}=0.450$ respectively.) The relationship between FEV1, FVC and blood 25-OH vitamin D levels are shown in Figure 1.

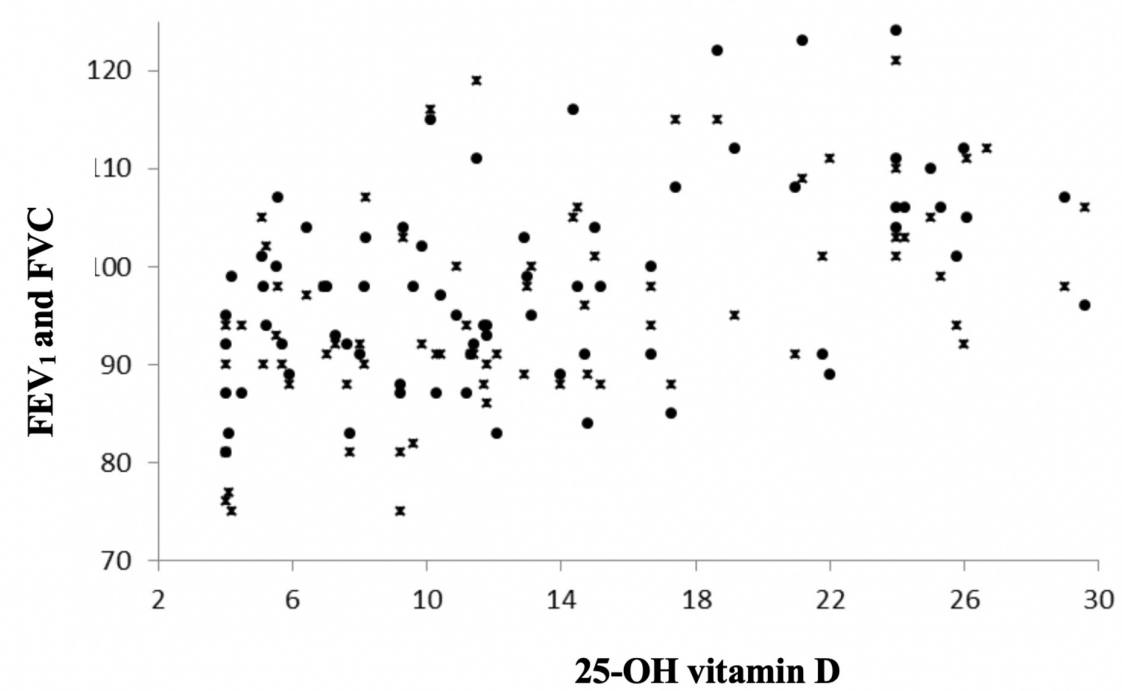

FIGURE 1: Association between blood 25-hydroxy (25-OH) vitamin D levels and pulmonary function tests in asthma patients 
There was no statistically significant difference between $25-\mathrm{OH}$ vitamin D levels and inhaled steroid usage in last 1 year $(9.15 \pm 5.18 \mathrm{ng} / \mathrm{ml}$ vs $9.65 \pm 4.78 \mathrm{ng} / \mathrm{ml}, \mathrm{p}=0,672)$. There was no correlation between the IgE levels of the patients and $25-\mathrm{OH}$ vitamin D levels $(\mathrm{p}=0.677, \mathrm{r}=-0.50)$. Also, there was no association between IgE and blood 25-OH vitamin D levels for patients with levels lower than $20 \mathrm{ng} / \mathrm{ml}$ or between $20-30 \mathrm{ng} / \mathrm{ml}$ $(\mathrm{p}>0.86, \mathrm{r}=-20)$.

\section{Discussion}

We found a remarkably high prevalence of low 25-OH vitamin D levels among the 6-15 year old control group and the asthma group. This finding clearly indicates that $25-\mathrm{OH}$ vitamin $\mathrm{D}$ deficiency is an important health problem in children living in Istanbul, Turkey. The insufficiency levels may be caused by limited sunshine exposure due to individuals' spending more time indoors or avoiding sunshine intentionally for fear of air pollution, skin pigmentation etc, or due to the covering of skin and low 25-OH vitamin D intake [14]. Also 25-OH vitamin D receptor (VDR) gene polymorphisms might be an important factor for genetic susceptibility to $25-\mathrm{OH}$ vitamin D deficiency in the Turkish population [15].

The functional consequences of VDR polymorphism in the population and its correlation with 25-OH vitamin D levels is an interesting topic for research. VDR polymorphism may explain why some patients with extremely low $25-\mathrm{OH}$ vitamin D levels are asymptomatic, and why different studies regarding vitamin D levels and asthma severity have found different results [16-17] however we could not measure 1.25 dihysroxyvitamin D levels in our study. This needs to be further studied.

Another factor to be pointed out is that the usage of food fortified by $25-\mathrm{OH}$ vitamin $\mathrm{D}$ is extremely low in Turkey when compared to other countries. In a study, 25-OH vitamin D deficiency was more prevalent among infants who did not receive supplementation with $25-\mathrm{OH}$ vitamin $\mathrm{D}$, and the seasonal effects were more pronounced in this group (78\% were deficient in winter vs $4 \%$ in summer) [16]. It should be noted, however, that one weak point of our study was that we did not determine $25-\mathrm{OH}$ vitamin $\mathrm{D}$ levels during the summer.

Another weak point of our study is the fact that we did not have the chance to evaluate other possible factors like race, sun exposure time and gene polymorphisms which might have important effects on the blood vitamin D levels. The fact that asthma patients might go outdoors less often compared to healthy children might be another reason for low vitamin D levels.

There was correlation between the 25-OH vitamin D levels and FEV1, FVC values as noted by other studies which include the observations that $25-\mathrm{OH}$ vitamin D levels are inversely associated with degree of worsening airflow limitation among asthmatics [17]. There was no relation between blood 25-OH vitamin D levels and the time from asthma diagnosis; number of attacks, inhaled steroid usage, anti-inflammatory medication (either ICS or leukotriene inhibitor) usage or systemic steroid usage in the previous year; atopy in the family, skin prick test positivity, 25-OH vitamin D usage in first year of life and the IgE level in asthma patients. Searing et al. showed that the $25-\mathrm{OH}$ vitamin D levels were markedly low in asthma patients using oral or inhaler steroids to control the disease and also patients with low 25-OH vitamin D levels had more frequent attacks and were in more steroid need compared to patients with normal $25-\mathrm{OH}$ vitamin D levels [18].

Some studies showed that 25-OH vitamin D supplementation might increase the effect of glucocorticoids in steroid resistant patients by increasing IL-10 production which is an anti-inflammatory mediator affecting the peripheral mononuclear cells $[11,19-20]$. One recent study showed that vitamin $\mathrm{D}$ alleviates airway remodeling by down-regulating the activity of Wnt/ $\beta$-catenin signaling pathway [21].

Our study population were found to have a mild asthma severity (mean FEV1=96.1 \pm 11.9 , mean FEV1/FVC=95.5 \pm 9.4$)$. A majority of the patients $(n=61,83 \%)$ had no symptoms at the time of the study. There may be two reasons for our findings of low $25-\mathrm{OH}$ vitamin D levels not being consistency with the severity of the disease. First, our patients had mild asthma with few attacks per year, and all of our population had 25-OH vitamin D levels below normal range. Secondly, genetic predisposition may influence the manifestation of 25-OH vitamin D deficiency. Although a large number of breast-fed infants have low serum 25-OH vitamin D levels, only a few of them manifest overt symptoms of 25-OH vitamin D deficiency. Moreover, obvious environmental factors such as lack of exposure to sunshine or inadequate 25-OH vitamin D intake are not associated with $25-\mathrm{OH}$ vitamin D deficiency in some patients. A study speculated that genetic predisposition may influence the manifestation of $25-\mathrm{OH}$ vitamin $\mathrm{D}$ deficiency [22].

In some studies it was emphasized that $25-\mathrm{OH}$ vitamin D supplementation in the first year of life has a negative correlation with pulmonary symptoms later in life whereas others pointed out that 25-OH vitamin $\mathrm{D}$ supplementation in the first year of life might increase the likelihood of asthma in the third decade of life $[5,23]$. We did not find any correlation between $25-\mathrm{OH}$ vitamin $\mathrm{D}$ supplementation in the first year of life 
and disease severity in our study. In a very recent study perinatal Vitamin D supplementation attenuates asthma development following traffic-related particulate matter exposure but does not help attenuate symptoms after asthma has been developed [24].

We found the 25-OH vitamin D levels of asthma groups lower than control groups. This supports the findings of other studies. Gupta et al. published a paper in 2011 showing that low 25-OH vitamin D levels increases the likelihood of asthma and other chronic pulmonary diseases by increasing airway smooth muscle mass [25].

Despite the great number of recently published studies on the relation of vitamin D with asthma there is still no consensus on considering $25-\mathrm{OH}$ vitamin $\mathrm{D}$ as an alternative single treatment for inflammatory diseases but is only adviced as a supplementation [26-27].

\section{Conclusions}

In this study, we found lower serum 25-OH vitamin D levels in asthmatic children when compared with controls, and we also found a relationship between serum 25-OH vitamin D levels and FEV1, FVC. We were able to show that 25-OH vitamin D insufficiency in childhood asthma is common yet similar to the general population. We were unable to find a relationship between the serum $25-\mathrm{OH}$ vitamin $\mathrm{D}$ levels and several markers of allergy and asthma severity. Our data suggest that additional prospective research needs to be performed to determine the potential beneficial role that $25-\mathrm{OH}$ vitamin $\mathrm{D}$ has on asthma.

\section{Additional Information \\ Disclosures}

Human subjects: Consent was obtained by all participants in this study. Kartal Training and Research Hospital IRB issued approval N/A. Local IRB approved this study. Animal subjects: All authors have confirmed that this study did not involve animal subjects or tissue. Conflicts of interest: In compliance with the ICMJE uniform disclosure form, all authors declare the following: Payment/services info: All authors have declared that no financial support was received from any organization for the submitted work. Financial relationships: All authors have declared that they have no financial relationships at present or within the previous three years with any organizations that might have an interest in the submitted work. Other relationships: All authors have declared that there are no other relationships or activities that could appear to have influenced the submitted work.

\section{References}

1. Bateman ED, Hurd SS, Barnes PJ: Global strategy for asthma management and prevention: GINA executive summary. Eur Respir J. 2008, 51(2):143-78. 10.1183/13993003.51387-2007

2. Akinbami LJ, Schoendorf KC: Trends in childhood asthma: prevalance, health care utilization and mortality . Pediatrics. 2002, 110(2 Pt1):315-22. 10.1542/peds.110.2.315

3. Liang L, Chantry C, Styne DM, Stephensen CB: Prevalence and risk factors for 25-OH vitamin D deficiency among healthy infants and young children in Sacramento, California. Eur J Pediatr. 2010, 169(11):1337-44. 10.1007/s00431-010-1226-3

4. Nicolaidou P, Hatzistamatiou Z, Papadopoulou A: Low 25-OH vitamin D status in mother-newborn pairs in Greece. Calcif Tissue Int. 2006, 78(6):337-42. 10.1007/s00223-006-0007-5

5. Litonjua AA, Weiss ST: Is 25-OH vitamin D deficiency to blame for the asthma epidemic . J Allergy Clin Immunol. 2007, 120(5):1031-1035. https://doi.org/10.1016/j.jaci.2007.08.028

6. Camargo CA JR, Rifas-Shiman SL, Litonjua AA, et al.: Maternal intake of 25-OH vitamin D during pregnancy and risk of recurrent wheeze in children at 3 y of age. Am J Clin Nutr. 2007, 85(3):788-95. 10.1093/ajcn/85.3.788

7. Worldwide variation in prevalence of symptoms of asthma, allergic rhinoconjunctivitis, and atopic eczema: ISAAC. The International Study of Asthma and Allergies in Childhood (ISAAC) Steering Committee. Lancet. 1998, 351(9111):1225-32. 10.1016/S0140-6736(97)07302-9

8. Wjst M: The 25-OH vitamin D slant on allergy . Pediatr Allergy Immunol. 2006, 17(7):477-83. 10.1111/j.13993038.2006.00456.x

9. Hatun S, Ozkan B, Bereket A: Vitamin D deficiency and prevention: Turkish experience . Acta Paediatr. 2011, 100(9):1195-9. 10.1111/j.1651-2227.2011.02383.x

10. Brehm JM, Schuemann B, Fuhlbrigge AL: 25-OH vitamin D levels and severe asthma exacerbations in the childhood asthma management program study. J Allergy Clin Immunol. 2010, 126(1):52-8. 10.1016/j.jaci.2010.03.043

11. Holick MF, Binkley NC, Bischoff-Ferrari HA: Evaluation, treatment, and prevention of vitamin D deficiency: an Endocrine Society clinical practice guideline. J Clin Endocrinol Metab. 2011, 96(7):1911-1930. 10.1210/jc.2011-0385

12. Miller MR, Hankinson J, Brusasco V, Burgos F, Casaburi R, Coates A: American Thoracic Society. Standardization of spirometry, 1994 update. American Thoracic Society. Am J Respir Crit Care Med. 1995, 152(3):1107-1136. 10.1164/ajrccm.152.3.7663792

13. Knudson RJ, Lebowitz MD, Holberg GJ, Burrows B: Changes in the normal maximal expiratory flow-volume curve with growth and aging. Am Rev Respir Dis. 1983, 127(6):725-734. 10.1164/arrd.1983.127.6.725

14. Andıran N, Celik N, Akca H, Doğan G: Vitamin D deficiency in children and adolescents . J Clin Res Pediatr Endocrinol. 2012, 4(1):25-29. 10.4274/jcrpe.574 
15. Bora G, Ozkan B, Dayangaç Eden D, Erdem Yurter H, Coşkun T: 25-OH vitamin D receptor gene polymorphisms in Turkish children with 25-OH vitamin D deficient rickets. Turk J Pediatr. 2008, 50:30-33.

16. Binkley N, Novotny R, Krueger D: Low $25-\mathrm{OH}$ vitamin D status despite abundant sun exposure . J Clin Endocrinol Metab. 2007, 92 (6):2130-5. 10.1210/jc.2006-2250

17. Alyasin A, Momen T, Kashef S, Alipour A, Amin R: The relationship between serum 25 hydroxy 25-OH vitamin D levels and asthma in children. Allergy Asthma Immunol Res. 2011, 3(4):251-255. 10.4168/aair.2011.3.4.251

18. Searing DA, Zhang Y, Murphy JR, Hauk PJ, Goleva E, Leung DY: Decreased serum 25-OH vitamin D levels in children with asthma are associated with increased corticosteroid use. J Allergy Clin Immunol. 2010, 125(5):995-1000. 10.1016/j.jaci.2010.03.008

19. Xystrakis E, Kusumakar S, Boswell S, Peek E, Urry Z, Richards DF: Reversing the defective induction of IL10-secreting regulatory T cells in glucocorticoid-resistant asthma patients. J Clin Invest. 2006, 116(1):146155. 10.1172/JCI21759

20. Wang W, Li JJ, Foster PS, Hansbro PM, Yang M: Potential therapeutic targets for steroid-resistant asthma . Curr Drug Targets. 2010, 11(8):957-970.

21. Huang Y, Wang L, Jia XX, Lin XX, Zhang WX: Vitamin D alleviates airway remodeling in asthma by downregulating the activity of Wnt/ $\beta$-catenin signaling pathway. Int Immunopharmacol. 2019, 68:88-94. 10.1016/j.intimp.2018.12.061

22. Kitanaka S, Isojima T, Takaki M, Numakura C, Hayasaka K, Igarashi T: Association of 25-OH vitamin Drelated gene polymorphisms with manifestation of 25-OH vitamin D deficiency in children. Endocr J. 2012, 59(11):1007-14. 10.1507/endocrj.EJ12-0143

23. Ginde AA, Mansbach JM, Camargo CA: $25-\mathrm{OH}$ vitamin D, respiratory infections and asthma . Curr Allergy Asthma Rep. 2009, 9(1):81-87.

24. Bolcas PE, Brandt EB, Zhang Z, Biagini Myers JM, Ruff BP, Khurana Hershey GK: Vitamin D supplementation attenuates asthma development following traffic-related particulate matter exposure. J Allergy Clin Immunol. 2019, 143(1):386-94. 10.1016/j.jaci.2018.04.042

25. Gupta A, Sjoukes A, Richards D, Banya W, Hawrylowicz C, Bush A, Saglani S: Relationship between serum $25-\mathrm{OH}$ vitamin D, disease severity and airway remodeling in children with asthma. Am J Respir Crit Care Med. 2011, 184(12):1342-9. 10.1164/rccm.201107-12390C

26. Litonjua AA: 25-OH vitamin D deficiency as a risk factor for childhood allergic disease and asthma . Curr Opin Allergy Clin Immunol. 2012, 12(2):179-85. 10.1097/ACI.0b013e3283507927

27. Causes of 25-OH vitamin D resistance and Deficiency . (2017). Accessed: March 20, 2019: https://www.uptodate.com/contents/causes-of-vitamin-d-deficiency-and-resistance. 